đáp ứng 95,2\%. không đáp ứng 4,8\%, phải thêm hoặc đổi kháng sinh.

Kết quả điều trị: Thành công 86,9\%, thất bại $13,1 \%$.

Các yếu tố liên quan đến kết quả điều tri: Trẻ có bệnh nền có tỉ lệ điều trị thành công thấp hơn nhóm không có bệnh nền $(O R=17,4, P<0,05)$. Trẻ có tiền căn tiếp xúc với người ho/ số mũi trong tuần qua có tỉ lệ điều trị thành công thấp hơn nhóm không tiếp xúc $(\mathrm{OR}=9, \mathrm{P}<0,05)$.

\section{TÀI LIÊU THAM KHẢO}

1. Giang CPH (2014), Đăc điểm lâm sàng, vi sinh và điểu trị của trẻ em viềm phổi nặng cần thở oxy tại bệnh viện Nhi Đồng 2, Luận văn tốt nghiệp Bác sĩ Nội trú, Đaai Hoc Y Dược TP Hồ Chí Minh, pp.

2. Harris $M$, Clark J, Coote $N$, et al. (2011), British Thoracic Society guidelines for the management of community acquired pneumonia in children: update 2011, Thorax, 66 Suppl 2(pp. ii1-23.
3. Jain DL, Sarathi V, Jawalekar S (2013), Predictors of treatment failure in hospitalized children [3-59 months] with severe and very severe pneumonia, Indian Pediatr, 50(8), pp. 787-9.

4. Jiang W, Wu M, Zhou J, et al. (2017), Etiologic spectrum and occurrence of coinfections in children hospitalized with community-acquired pneumonia, BMC Infect Dis, 17(1), pp. 787.

5. Liu JW, Chen YH, Lee WS, et al. (2019), Randomized Noninferiority Trial of CefoperazoneSulbactam versus Cefepime in the Treatment of Hospital-Acquired and Healthcare-Associated Pneumonia, Antimicrob Agents Chemother, 63(8), pp.

6. Igor Rudan aCB-P, b Zrinka Biloglav, C Kim Mulhollandd \& Harry Campbelle (2008), Epidemiology and etiology of childhood pneumonia, Bulletin of the World Health Organization 86(5), pp. 408-416.

7. WHO (2005), Hospital care for children Guidelines for the management of common childhood illnesses, Second edition, pp. pp. 80-91.

\title{
SO SÁNH HIÊU QUẢ LÀM SACCH DẠ DÀY BẰNG EPUMISAN TRONG CHUẨN BI NGƯỜI BẾNH NộI SOI TIÊU HÓA TRÊN TẠI TRUNG TÂM NộI SOI - BỆNH VIỆN ĐẠI HỌC Y HÀ NộI
}

\author{
Đào Viết Quân*, Lê Quang Hưng*, Hoàng Cẩm Tú*, \\ Đỗ Thị Việt Phương*, Trần Đình Thảo*, Đào Văn Long*
}

\section{TÓM TẮT}

Mục tiêu: Đánh giá hiệu quả làm sạch dạ dày bằng Ėpumisan trong chuẩn bị người bệnh nội soi tiêu hóa trên tại Trung tâm nội soi bệnh viện đại học Y Hà Nội năm 2020-2021. Đối tượng và phương pháp nghiên cứu: Các người bệnh ngoại trú có chỉ định nội soi đường tiêu hóa trên được phẩn ngẫu nhiên vào 2 nhóm: nhóm sử dung Epumisan(Simethicone) và nhóm chứng không sử dụngchấtlàm tan bọt từ tháng 3/2020 tới tháng 3/2021 theo phương pháp thử nghiệm lâm sàng đối chứng ngẫu nhiên. Tất cả cuộc nội soi đều được thực hiện bằng máy nội soi tiêu hóa trên Fujinon, và đánh giá kết quả theo thang điểm của Mc Nally. Kết quả: 1040 người bênh đáp ứng tiêu chuẩn được đưa vào nghiên cứu. Tỷ lệ người bệnh có sử dụng Ėpumisan(Simethicone) có hiệu quả tan bọ ở mức độ $\mathrm{A}$ theo thang $\mathrm{Mc}$ Nally cao hơn hẳn so với nhóm chứng không sử dụng với $p<0,001$. Kết luận: Chuẩn bị nội soi tiêu hóa trên bằng Espumisan làm giảm ứ đọng bot ở thực quản, dạ dày và hành tá tràng một cách hiệu quả, giúp quan sát, định hướng chẩn đoán các tổn thương nhỏ rô ràng, chính xác hơn.

*Trung tâm Nọi soi - Bệnh viện Đại học Y Hà Nội Chịu trách nhiệm chính: Đào Viết Quấn

Email: quandv0083@hmuh.vn

Ngày nhận bài: 5.3.2021

Ngày phản biên khoa học: 27.4.2021

Ngày duyệt bài: 11.5.2021
Tư khóa: Espumisan, Simethicone, nội soitiêu hóa trên, tan bọt

\section{SUMMARY}

\section{COMPARISON EFFECTS OF CLEANING} STOMACH BY EPUMISAN IN PREPARATION OF SUPER GASTROINTESTINAL ENDOSCOPY PATIENTS AT ENDOSCOPIC CENTER - HANOI MEDICAL UNIVERSITY HOSPITAL

Objectives: To evaluate the effect of foam cleaning of Espumisan (Simethicone) in patients with upper gastrointestinal endoscopy at Hanoi Medical University Hospital. Methods: Outpatients with indications for upper gastrointestinal endoscopy were randomly assigned to 2 groups: the Simethicone (Espumisan) and the control group, from March 2020 to March 2021, by the method of randomized controlled clinical trial. All endoscopy was performed using a gastrointestinal endoscopy on Fujinon, and evaluated the results on a scale of Mc Nally. Results: 1040 patients who met the criteria were included in the study. The percentage of level A (complete bubble cleaniness) in esophagus, stomach body, fundus, antrum, and duodenum of patients using Espumisan are higher than those of control group ( $p<0.00001)$. Conclusion: The preparation of upper gastrointestinal endoscopy with Espumisan reduces the stagnation of foam in the esophagus, stomach and duodenum effectively, helping to observe and 
diagnose small lesions more clearly and accurately.

Key words: Simethicone, upper gastrointestinal endoscopy, defrosting, foam cleanliness

\section{I. ĐĂT VẤN ĐỀ}

Bọt ở đường tiêu hóa trên là một trong những nguyên nhân chính làm cản trở khi quan sát tổn thương nhỏ ngay cả khi người bệnh đã tuân thủ việc nhịn ăn uống hoàn toàn trước cuộc soi. Việc nghiên cứu phương pháp chuẩn bị làm sạch đường tiêu hóa luôn đóng một vai trò rất quan trọng để cuộc soi được tiến hành nhanh chóng và tránh bỏ sót các tổn thương nhỏ ở thân vị, phình vị và hang vị. Epumisan (Simethicone) là một chất làm tan bọt, chống đầy hơi và đã được sử dụng ở nhiều nước để chuẩn bị nội soi đường tiêu hóa trên. Tuy nhiên cho đến hiện tại ở Việt Nam mới chỉ có một số ít bệnh viện ứng dụng phương pháp chuẩn bị nội soi này, và áp dụng một cách không thường xuyên. Nghiên cứu này được tiến hành với mục tiêu: Đánh giá hiệu quả làm sạch da dày bằng Espumisan (Simethicone) trong chuẩn bị người bệnh nội soi tiêu hóa trên tại Trung tâm nội soi bệnh viện đại học Y Hà Nội năm 2020-2021

\section{II. ĐỐl TƯỢNG VÀ PHƯƠNG PHÁP NGHIÊN CỨU}

2.1. Đối tượng nghiên cứu: Gồm những người bệnh ngoại trú đến khám bênnh tại bệnh viện Đại học Y Hà Nội, được chia ngẫu nhiên vào nhóm can thiêp và nhóm chứng thỏa mãn tiêu chuẩn chọn mẩu dưới đâu

- Được chỉ định nội soi đường tiêu hóa trên, không gây mê trong khoảng thời gian từ tháng $3 / 2020$ đến $3 / 2021$

- Được tiến hành thủ thuật nội soi da dày - tá tràng không gây mê tại Trung tâm Nội Soi của bệnh viện trong thời gian nói trên

- Người bệnh đủ điều kiện sức khỏe để thực hiện thủ thuật nội soi đường tiêu hóa trên, đảm bảo nhịn ăn uống tối thiểu 8 giờ trước khi tiến hành thủ thuật nội soi

- Đồng ý tham gia vào nghiên cứu

Tiêu chuẩn loại trừ gồm những người bệnh được chỉ định soi dạ dày cấp cứu; có biểu hiện xuất huyết tiêu hóa trên (nônramáu - đi ngoài phân đen), hoặc đang sử dụng các nhóm thuốc antacid; người bệnh mắc các bệnh lý như co thắt tâm vị, hẹp môn vị.

Phương pháp chọn mẫu ngẫu nhiên hệ thống được áp dụng để mời đối tượng tham gia nghiên cứu vào nhóm chứng và nhóm can thiệp với Cõ mẫu ở mỗi nhóm được ước tính theo công thức sau. $a=0,05 ; \beta=0,8$

P1: Tỷ lệ người bệnh đạt mức độ $\mathrm{A}$ ở nhóm can thiệp (ước tính $\mathrm{P}_{1}=0,9$ )

P2: Tỷ lệ ngườ ibệnh đạt mức độ $\mathrm{A}$ ở nhóm chứng (ước tính $\mathrm{P}_{2}=0,8$ )

$$
\mathrm{n}=\frac{\left\{z_{1-\boldsymbol{z} / 2} \sqrt{2 \overline{\mathrm{P}}(1-\overline{\mathrm{P}})}+z_{1-\beta} \sqrt{\mathrm{P}_{1}\left(1-\mathrm{P}_{1}\right)+\mathrm{P}_{2}\left(1-\mathrm{P}_{2}\right)}\right\}^{2}}{\left(\mathrm{P}_{1}-\mathrm{P}_{2}\right)^{2}}
$$

Vậy cõ̃ mẫu tối thiểu cho mỗi nhóm là 199. Với số lượng người bệnh soi dạ dày hàng năm tại trung tâm nội soi bệnh viện Đại học $Y$ Hà Nội là khoảng 10.000 năm. Dự kiến sẽ mời khoảng 500 người bệnh/ mỗi nhóm tham gia vào nghiên cứu.

2.2. Thiết kế nghiên cứu:Can thiệp lâm sàng bệnh chứng được áp dụng với can thiệp là Epumisan (Simethicone) được pha với liều từ 8 $\mathrm{ml}$ (tương đương 320mg) Espumisan với $60 \mathrm{ml}$ nước cất với liều tối đa Espumisan để có thể đạt được hiệu quả cao nhất trong việc chuẩn bị nội soi đường tiêu hoá trên.

2.3. Công cụ nghiên cứu: Người bệnh đạt tiêu chuẩn lựa chọn được hỏi bệnh và khám lâm sàng và khai thác từ hồ sơ bệnh án. Các thông tin được điền vào bệnh án nghiên cứu mẫu. Tất cả ca nội soi đều được thực hiện bằng máy nội soi tiêu hóa trên Fujinon. Việc đánh giá mức độ tan bo - làm sạch da dày của người bệnh được tiến hành trên 4 vùng (thực quản, thân vị phình vị, hang vị và tá tràng) do các bác sĩ thực hiện một cách ngẫu nhiên cuộc soi trực tiếp ghi nhận dựa trên phân độ ảnhtheo 4 mức độ theo thang điểm của Mc Nally. Thang điểm Mc Nally gồm mức $A$ (sạch bọt hoàn toàn), mức $B$ (Vùng khảo sát còn ít bọt nhưng hầu như không ảnh hưởng quan sát); mức $C$ (Vùng khảo sát còn nhiều bọt, phải dùng $50 \mathrm{ml}$ để rửa) và mức $D$ (Vùng khảo sát còn rất nhiều bọt, vón cục, cần rửa $>100 \mathrm{ml}$ nước mới quan sát được)

2.4. Phân tích số liệu: Dữ liệu được nhập và phân tích bằng phần mểm SPSS 16.0. Các thuật toán mô tả được áp dụng như tỷ lệ phần trăm, trung bình, độ lệch chuẩn, và được biểu diễn qua các biểu độ. Thuật toán thống kề phân tích được sử dụng như Khi-bình phương cũng được sử dụng để tìm hiểu hiệu quả làm sạch dạ dày.

2.5.Đạo đức nghiên cứu: Nghiên cứu tuân thủ các quy định về nghiên cứu y sinh. Mọi thông tin về người bệnh được bảo mật và chỉ được sử dụng khi có sự chấp thuận của người bệnh. Nghiên cứu được Hội đồng Khoa học Bệnh viện cho phép thực hiện và Ban Giám đốc bệnh viện, lãnh đạo Trung tâm Nội soi ủng hộ tiến hành.

\section{KẾT QUẢ NGHIÊN CỨU}

Từ tháng 03/2020 đến tháng 03/2021, có 1040 người bệnh đến nội soi dạ dày tại Trung 
tâm nôi soi \& Nôi soi can thiêp - Bênh viện Đai học $Y$ Hà Nội đáp ứng đủ tiểu chuẩn tham gia nghiên cứu. Bảng 1 đến bảng 4 tóm tắt kết quả đánh giá mức độ làm sạch bọt theo thang điểm Mc Nally tại 4 vùng tương ứng của nhóm can thiệp (có sử dụng Simethicone) và nhóm chứng (không sử dụng).

Bảng 1. Mức độ bọt ở thức quản giữa 2
nhóm
\begin{tabular}{|c|c|c|}
\hline $\begin{array}{c}\text { Mức độ } \\
\text { bọt }\end{array}$ & $\begin{array}{c}\mathbf{N h o ́ m ~ c a n ~ t h i e ̣ ̂ p ~} \\
(\mathbf{N}=\mathbf{5 3 0}) \mathbf{n} \%\end{array}$ & $\begin{array}{c}\mathbf{N h o ́ m} \text { chứng } \\
(\mathbf{N}=\mathbf{5 1 0}) \mathbf{n} \%\end{array}$ \\
\hline A & $521(98,3)$ & $332(65)$ \\
\hline B & $9(1,7)$ & $161(31,6)$ \\
\hline C & $0(0)$ & $17(3,4)$ \\
\hline
\end{tabular}

Nhân xét: Cả 2 nhóm đều không có người bệnh nào có mức $D$ theo đánh giá của Mc Nally, số người bệnh của nhóm can thiệp đạt mức $A$ cao hơn hẳn so với nhóm chứng $(98,3 \%$ vs. $65 \%)$. Nhóm can thiệp không có trường hợp nào đạt mức $\mathrm{C}$, trong khi đó nhóm chứng vẩn còn $3,4 \%$ đối tượng được đánh giá mức $\mathrm{C}$ theo thang điểm Mc Nelly

$\begin{gathered}\text { Bảng 2. Mức độ bọt ở vùng thân và } \\
\text { phình vị }\end{gathered}$
\begin{tabular}{|c|c|c|}
\hline $\begin{array}{c}\text { Mức độ } \\
\text { bọt }\end{array}$ & $\begin{array}{c}\text { Nhóm can thiệp } \\
(\mathbf{N}=\mathbf{5 3 0}) \mathbf{n} \%\end{array}$ & $\begin{array}{c}\text { Nhómchứng } \\
(\mathbf{N}=\mathbf{5 1 0} \mathbf{n} \mathbf{n} \%\end{array}$ \\
\hline A & $404(76,2)$ & $140(27,5)$ \\
\hline B & $80(15,1)$ & $260(51)$ \\
\hline C & $46(8,7)$ & $70(13,7)$ \\
\hline D & $0(0)$ & $40(7,8)$ \\
\hline
\end{tabular}

Nhân xét: Có tới 7,8\% người bênh của nhóm chứng được đánh giá có mức độ làm sạch bọt ở mức $\mathrm{D}$, trong khi đó không có người bệnh nào ở nhóm can thiệp được đánh giá mức này. Tỷ lệ người bệnh của nhóm can thiệp được đánh giá ở mức $A$ và $B$ cao hơn hẳn so với nhóm chứng

\section{Bảng 3. Mức độ bọt ở vùng hang ví}

\begin{tabular}{|c|c|c|}
\hline $\begin{array}{c}\text { Mức độ } \\
\text { bọt }\end{array}$ & $\begin{array}{c}\text { Nhóm can thiệp } \\
(\mathbf{N = 5 3 0 )} \mathbf{n} \%\end{array}$ & $\begin{array}{c}\text { Nhómchứng } \\
(\mathbf{N}=\mathbf{5 1 0}) \mathbf{n} \%\end{array}$ \\
\hline A & $503(94,9)$ & $330(64,7)$ \\
\hline B & $21(4,0)$ & $126(24,7)$ \\
\hline C & $6(1,1)$ & $40(7,8)$ \\
\hline D & $0(0)$ & $14(2,8)$ \\
\hline
\end{tabular}

Nhân xét: Tỷ lệ người bệnh của nhóm can thiệp được đánh giá ở mức $\mathrm{A}$ cao hơn hẳn so với nhóm chứng (94,9\% vs. 63,7\%). Vẫn còn $14 \mathrm{ca}$ trong nhóm chứng được đánh giá mức $\mathrm{D}$.

$\begin{gathered}\text { Bảng 4. Mức độ bọt ớ vùng hành tá } \\
\text { tràng }\end{gathered}$
\begin{tabular}{|c|c|c|}
\hline $\begin{array}{c}\text { Mức độ } \\
\text { bọt }\end{array}$ & $\begin{array}{c}\mathbf{N h o ́ m ~ c a n ~ t h i e ̣ ̂ p ~} \\
(\mathbf{N}=\mathbf{5 3 0}) \mathbf{n} \%\end{array}$ & $\begin{array}{c}\mathbf{N h o ́ m c h u ̛ ́ n g ~} \\
(\mathbf{N}=\mathbf{5 1 0} \mathbf{n} \mathbf{n}\end{array}$ \\
\hline$\dot{A}$ & $512(96,9)$ & $371(72,8)$ \\
\hline B & $18(3,4)$ & $120(23,5)$ \\
\hline C & $0(0)$ & $19(3,7)$ \\
\hline
\end{tabular}

Nhận xét: Cả 2 nhóm đều không có người bệnh nào có mức $D$ theo đánh giá của Mc Nally, số người bệnh của nhóm can thiệp đạt mức $A$ cao hơn hẳn so với nhóm chứng $(96,9 \%$ vs. $72,8 \%$ ). Nhóm can thiệp không có trường hợp nào đạt mức $\mathrm{C}$, trong khi đó nhóm chứng vẫn còn $3,7 \%$ đối tượng được đánh giá mức $\mathrm{C}$ theo thang điểm Mc Nelly

Thuật toán thống kê phân tích được áp dụng để so sánh hiêu quả làm sạch da dày giữa nhóm can thiệp và nhóm chứng được tóm tắt ở bảng 5 .

Bảng 5. So sánh mức độ làm sạch da dày giữa hai nhóm nghiên cứu

\begin{tabular}{|c|c|c|c|c|}
\hline Vị trí & $\begin{array}{l}\text { Mức độ } \\
\text { bọt }\end{array}$ & $\begin{array}{l}\text { Nhóm can thiệp } \\
(N=530) n \%\end{array}$ & $\begin{array}{c}\text { Nhóm chứng }(\mathrm{N}=510) \\
n \%\end{array}$ & $\chi^{2} ; \mathbf{p}$ \\
\hline \multirow[b]{2}{*}{ Vùng thực quản } & A & $521(98,3)$ & $332(65)$ & \multirow{2}{*}{$\begin{array}{l}194,29 ; \\
p<0,001\end{array}$} \\
\hline & B, C & $9(1,7)$ & $178(35)$ & \\
\hline \multirow{3}{*}{$\begin{array}{l}\text { Vùng thân - } \\
\text { phinh vị }\end{array}$} & A & $404(76,2)$ & $140(27,5)$ & \multirow{3}{*}{$\begin{array}{l}249,38 ; \\
\mathrm{p}<0,001\end{array}$} \\
\hline & B & $80(15,1)$ & $260(51)$ & \\
\hline & C,D & $46(8,7)$ & $110(21,5)$ & \\
\hline \multirow{3}{*}{ Vùng hang vị } & A & $503(94,9)$ & $330(64,7)$ & \multirow{3}{*}{$\begin{array}{l}148,99 ; \\
p<0,001\end{array}$} \\
\hline & B & $21(4,0)$ & $126(24,7)$ & \\
\hline & C,D & $6(1,1)$ & $54(10,6)$ & \\
\hline \multirow{2}{*}{$\begin{array}{l}\text { Vùng hành tá } \\
\text { tràng }\end{array}$} & $\mathbf{A}$ & $512(96,9)$ & $371(72,8)$ & \multirow{2}{*}{$\begin{array}{l}1154,43 ; \\
p<0,001\end{array}$} \\
\hline & B, C & $18(3,4)$ & $139(27,2)$ & \\
\hline
\end{tabular}

Nhận xét: Tỷ lệ người bệnh có mức độ làm sach mức $A$ theo thang Mc Nelly của nhóm can thiệp cao hớn hẳn so với nhóm chứng ở cả 4 vùng đánh giá. Hiệu quả làm sạch dạ dày ở các các mức khác $B, C$ cũng tốt hơn giữa nhóm can thiệp và nhóm chứng.

\section{BÀN LUẬN}

Epumisan(Simethicone) thực chất là một hỗn hợp của Dimethon và $4-7 \%$ Silicone dioxide. Dimethicone và Simethicone là những thành phần hoạt động tích cực trong việc làm giảm các triệu chứng đầy hơi, và an toàn với niêm mạc (1). Với những đắc điểm đó, Simethicone đã được ứng dựng để làm giảm cảm giác đầy hơi, 
trướng khí, khó chịu, ợ nóng, loét dạ dày, hội chứng ruột kích thích, và suy tụy, cũng như để chuẩn bị người bệnh làm xét nghiệm (2). Thuốc đã được chứng minh an toàn cho người lớn, trẻ em và trẻ sơ sinh, đặc biệt là những trường hợp bị đầy hơi do hội chứng co thắt ruột $(1,3)$. Trong nghiên cứu này, chúng tôi đánh giá hiệu quả khác của simeticone, đó là sử dụng Simethicone trong chuẩn bị nội soi dạ dày tá tràng.

Nội soi dạ dày ruột (thực quản nội soi nội soi hoặc EGD) là một trong những phương pháp chẩn đoán và điều trị phổ biến nhất của các bệnh trên dạ dày-ruột (4). Tuy nhiên, một hạn chế của phương pháp này là sự hiện diện của bong bóng khí và bọt trong dạ dày và tá tràng, do đó bác sĩ rất khó, hoăc đôi khi không thể đánh giá niêm mạc bằng cách sử dụng những hình ảnh thu được khi có bong bóng. Điều này sẽ làm giảm độ chính xác chẩn đoán, thời gian nội soi kéo dài, và giảm hiệu quả điều trị của người bệnh(5). Do đó, loại bỏ các bong bóng là công tác chuẩn bị cần thiết cho nội soi dạ dày tá tràng.

Bên cạnh đó, việc lựa chọn được phương pháp chuẩn bị thích hợp có thể loại bỏ các bong bóng, không có các phản ứng phụ, và có thể áp dụng cho hầu hết người bệnh trong các điều kiện khác nhau là rất quan trọng (6). Hiện nay, ngoại trừ việc nhịn ăn trước khi nội soi, không có phương pháp chuẩn nào được đề nghị để chuẩn bị trước cho EGD. Mặc dù Simethicone được sử dụng phổ biến để để chuẩn bị nội soi, tuy nhiên, khi tìm kiếm tài liệu để thực hiện nghiên cứu này, chúng tôi thấy số lượng nguyên cứu tương đối ít làm về đề tài đánh giá hiệu quả của simethicone trong nội soi và các tác dụng không mong muốn, trong đó nhiêu nghiên cứu đã cũ (7-9).

Epumisan(Simethicone) có tính sinh lý không hoạt động và không độc. Có thể dùng đường uống và không thể hấp thu qua hệ thống đường tiêu hóa. Bằng cách giảm lực bám dính của bong bóng khí, Simethicone loại bỏ các bong bóng. Do đó, người ta hy vọng rằng thuốc có thể được sử dụng để loại bỏ bọt và dạ dày, tá tràng và bong bóng tá tràng. Simethicone không có bất kỳ sự tương tác thuốc đã biết, và không có báo cáo về biến chứng đáng kể cho nó. Hơn nữa, thuốc (trong công thức dung dịch) đã được sử dụng trong một số nghiên cứu để chuẩn bị đường ruột trước khi nội soi và nội soi nang. Tuy nhiên, cho đến nay, không có báo cáo đáng tin cậy nào đối với việc sử dụng thuốc thường xuyên để chuẩn bị trước khi tiêm EGD. Như vậy, chúng tôi đã đánh giá tác dụng của Simethicone đối với việc giảm bọt khí và bọt khí trong quá trình nội soi dạ dày-ruột.

Trong nghiên cứu của chúng tôi, ở cả 4 khu vực: thực quản, thân và phình vị, hang vị và hành tá tràng, tî lệ người bệnh đạt mức độ sạch bọt hoàn toàn (mức độ $A$ ) để khảo sát niêm mạc đường tiêu hóa trên ở nhóm sử dụng Espumisan cao hơn nhóm không sử dụng có ý nghĩa thống kê $(p<0.00001)$. Kết quả này cũng tương tự với kết quả tìm thấy trong nghiên cứu mới nhất chúng tôi tìm được của tác giả Majid Ahsan (2011). Trong nghiên cứu thử nghiệm ngẫu nhiên có đối chứng của Majid, so sánh giữa nhóm nghiên cứu 90 người bệnh và nhóm chứng 83 người bệnh, họ thây sự giảm lượng bọt đáng kể ở dạ dày của nhóm nghiên cứu sử dụng Espimusan với $p=0.002$. Khác với nghiên cứu của chúng tôi, họ lại không thấy sự khác biệt trong lượng bọt bóng giảm ở hành tá tràng với $p=0,42$. Điêu này có thể lý giải là do việc nghiên cứu của chúng tôi lựa chọn cho người bệnh uống liều tối đa để đánh giá hiệu quả cao nhất khi sử dụng, trong khi nghiên cứu của Ahsan sử dụng liều thấp hơn. Dó đó, thuốc tới dạ dày vẫn đủ lượng để xuống tới hành tá tràng, trong khi trong nghiên cứu của Ahsan, thuốc tới dạ dày và chưa đủ lượng để tới giảm bọt tại hành tá tràng. Điều này cũng hợp lý khi chúng tôi đánh giá hiệu quả giảm bọt khí theo Mc Nally và kết quả cho ra đạt mức A- mức tốt nhất, trong khi nghiên cứu của Ahsan kết quả giao động từ 0 tới 2 trên 4 thang điểm họ sử dụng: 0 - không có bọt khí, 1lượng bọt rất nhỏ, không ảnh hưởng tới quan sát, 2- lượng bọt khí tương đối, có ảnh hưởng tới quan sát, 3- lượng bọt khí nhiếu khiến việc quan sát rất khó khăn. Tuy nhiên, chúng tổi nhận định thây rằng việc rửa bọt tại vị trí này rất đợn giản nên sự khác biệt có nghĩa thống kê ở khu vực này hay không hầu như không làm thay đổi có ý nghĩa quá trình nội soi tại đây.

Espumisan (Simethicone) là tác nhân phá bọt, không vị, không mùi, không được hấp thu qua niêm mạc đường tiêu hóa, hiếm khi có tương tác thuốc và có thể dùng đến $900 \mathrm{mg} / \mathrm{ngày}$ mà không gây bất kỳ độc tính nào. Espumisan (Simethicone) đóng vai trò chủ yếu trong lòng đường tiêu hóa với chức năng chống tạo bọt và bảo vệ niêm mạc dạ dày. Nó hoạt động bằng cách làm giảm sức căng bề mặt của bong bóng khí bằng cách gom lại các bong bóng nhỏ và sau đó có thể dễ dàng loại bỏ khỏi đường tiêu hóa. Do đó, việc sử dụng Espumisan trong nội soi đường tiêu hóa trên cho thấy hiệu quả tốt trong việc loại bỏ bọt và bong bóng khí.

Kết quả nghiên cứu này cho thấy ưu thế vượt 
trôi của việc chuẩn bi nội soi tiêu hóa trên với Espumisan so với việc không sử dụng: tỉ lệ sạch bọt ở mức lý tưởng (mức $A$ ) cho việc quan sát trên nội soi để khảo sát tổn thương đều cao hơn hẳn có ý nghĩa thống kê so với nhóm không sử dụng. Thực tế trong khi thực hiện nghiên cứu, chúng tôi nhận thấy giảm rõ rệt tình trạng bọt khí ở đường tiêu hóa, quá trình thực hiện nội soi cho người bênh được tiến hành nhanh chóng và thuận lợi; bác sĩ nội soi rất hiếm khi phải tiến hành bớm rửa để quan sát, người bệnh dễ chịu hơn rõ rệt.

Simethicone được thống kê dùng trong làm sạch đường tiêu hóa, đã chứng minh hiệu quả tốt khi phá võ̃ các bọt khí và bong bóng trong suốt quá trình nội soi đường tiêu hóa trên. Hơn nữa, dùng Simethicone trước nội soi có thể tăng cường khả năng hiển thị nội soi ở tất cả các vùng trên đường tiêu hóa trên, cải thiện cả kết quả nội soi và sự hài lòng của người bệnh, thêm vào đó rút ngắn thêm thời gian dùng Simethicone bổ trợ làm sạch đường tiêu hóa. Do đó, Simethicone dùng đường uống được chứng minh là chất chống tạo bọt tốt cho nội soi đờng tiêu hóa trên.

Kết quả nghiên cứu về hiệu quả làm giảm bọt trong khi soi dạ dày tá tràng cũng tương đồng với 13 nghiên cứu được một tổng quan tài liệu có hệ thống (systematic review) thực hiện nghiên cứu phân tích tổng hợp (meta-analysiss). Việc làm giảm đáng kể bọt khí trong nội soi dẫn tới tăng khả năng hiển thị, tạo điều kiện và tăng cơ hội trong việc đánh giá và chẩn đoán chính xác hơn. Đó là về mặt lý luận, còn về mặt nghiên cứu số liệu thực tiễn, chúng tôi chưa thẩy nghiên cứu nào đánh giá hiệu quả của việc sử dụng Espumisan trong hiệu quả chuẩn đoán tổn thương bệnh lý, đây cũng là hạn chế của nghiên cứu của chúng tôi.

Một hạn chế nữa của nghiên cứu này là, mặc dù đây là môt nghiên cứu thử nghiệm lâm sàng đối chứng ngẫu nhiên, sử dụng biện pháp làm mù nghiên cứu viên và người bệnh tham gia nghiên cứu nhằm hạn chế sai số (bias), tuy nhiên việc có 04 bác sĩ nội soi đánh giá qua hình ảnh có thể có những sai số nhất định trong đánh giá và nhận định kết quả. Mặc dù vậy, chúng tôi khá tự tin về kết quả thu được, do theo phân loại của Mc Nally, loại $A$ - sach bot hoàn toàn và loại $B$ - có một ít bọt được phân chia rất rõ ràng, việc chẩn đoán nhầm giữa 2 mức độ này cũng khó xảy ra.

\section{KẾT LUÂN}

Nghiên cứu được thực hiện từ tháng 03/2020 đến tháng 03/2021 nhằm đánh giá hiệu quả làm tan bọt của Espumisan (Simethicone) trong chuẩn bị nội soi đường tiêu hoá trên tại trung tâm nội soi bệnh viện Đại học Y Hà Nội. Tổng cộng có 1040 người bệnh ngoại trú đến nội soi dạ dày tại Trung tâm nội soi \& Nội soi can thiệp - Bệnh viện Đại học $Y$ Hà Nội đáp ứng đủ tiêu chuẩn tham gia nghiên cứu. Sau khi tiến hành nghiên cứu, chúng tôi rút ra kết luận: Tỉ lệ người bệnh đạt mức độ sạch bọt hoàn toàn (mức độ $A$ ) để khảo sát niêm mạc đường tiêu hóa trên ở nhóm sử dụng Espumisan cao hơn nhóm không sử dụng ở thực quản, thân vị, phình vị, hang vị và hành tá tràng có ý nghĩa thống kê $(p<0.00001)$

Kiến nghị: Tuy nhiên, nghiên cứu đánh giá hiệu quả của Espumisan tại Việt Nam còn ít, do đó, cần thêm các nghiên cứu trên quần thể người bệnh khác nhau nhằm khẳng định hơn hiệu quả thực sự của Espumisan trong việc làm giảm bọt trong chuẩn bị người bệnh soi dạ dày tá tràng, cũng như hiệu quả trong rút ngắn thời gian soi và tăng chất lượng hình ảnh khi soi.

\section{TÀI LIẸU THAM KHẢO}

1. Mojsiewicz-Pieńkowska K. Review of Current Pharmaceutical Applications of Polysiloxanes (Silicones), in Handbook of Polymers for Pharmaceutical Technologies: Processing and Applications, Volume 2 (eds V. K. Thakur and M. K. Thakur), John Wiley \& Sons, Inc., Hoboken, NJ, USA. 2015.

2. Bueno $L$, Beaufrand $C$, Theodorou V, AndroDelestrain $\mathbf{M}-\mathbf{C}$. Influence of simethicone and alverine on stress-induced alterations of colonic permeability and sensitivity in rats: beneficial effect of their association: Alverine, simethicone and vsiceral pain. Journal of Pharmacy and Pharmacology. 2013;65(4):567-73.

3. Kheir AEM. Infantile colic, facts and fiction.Italian Journal of Pediatrics. 2012;38(1):34-.

4. Cohen J, Safdi MA, Deal SE, Baron TH, Chak A, Hoffman B, et al. Quality Indicators for Esophagogastroduodenoscopy. The American Journal of Gastroenterology. 2006;101(4):886-91.

5. Kwan V, Devière J. Endoscopy essentials: preparation, sedation, and surveillance. Endoscopy. 2008:40(01):65-70.

6. Enns R. Capsule endoscopy: in search of the ideal image. The American Journal of Gastroenterology. 2008;103(1):83-5.

7. Banerjee B, Parker J, Waits W, Davis B. Effectiveness of preproceduresimethicone drink in improving visibility during esophagogastroduodenoscopy: A double-blind, randomized study [2]. Journal of clinical gastroenterology. 1992;15(3):264-5.

8. Bertoni G, Gumina C, Conigliaro R, Ricci E, Staffetti J, Mortilla $M$, et al. Randomized placebo-controlled trial of oral liquid simethicone prior to upper gastrointestinal endoscopy. Endoscopy. 1992;24(04):268-70. 